\title{
Multiple drug resistance in the canine hookworm Ancylostoma caninum: an emerging threat?
}

\author{
Pablo D. Jimenez Castro ${ }^{1,2^{*}}$, Sue B. Howell ${ }^{1}$, John J. Schaefer ${ }^{3}$, Russell W. Avramenko ${ }^{4}$, John S. Gilleard ${ }^{4}$
} and Ray M. Kaplan'

\begin{abstract}
Background: The canine hookworm, Ancylostoma caninum is the most prevalent and important intestinal nematode parasite of dogs in the USA. Hookworms are typically well controlled by treatment with all commonly used anthelmintics that are approved for this use in dogs. However, in the past few years, cases of recurrent/persistent canine hookworm infections appear to have dramatically increased, suggesting that anthelmintic resistance (AR) may have evolved in this parasite. These cases are highly overrepresented by greyhounds, but multiple other breeds are also represented. The aim of this study was to characterize several of these suspected resistant isolates using in vitro, genetic and clinical testing to determine if these cases represent true anthelmintic resistance in A. caninum.

Methods: Fecal samples containing hookworm eggs from three cases of persistent hookworm infections; one from a greyhound, one from a miniature schnauzer and one from a hound-mix, were received by our laboratory. These were then used to establish infections in laboratory dogs and to perform egg hatch assays (EHA) and larval development assays (LDA) for detecting resistance to benzimidazoles and macrocyclic lactones, respectively. Additional EHA and LDA were performed on eggs recovered from the laboratory-induced infections. Fecal egg count reduction tests were performed to detect resistance to pyrantel. Deep amplicon sequencing assays were developed to measure the frequency of non-synonymous single nucleotide polymorphisms (SNP) at codons 167, 198 and 200 of the A. caninum isotype-1 $\beta$-tubulin gene.

Results: Resistance ratios for the three A. caninum isolates tested ranged from 6.0 to $>100$ and 5.5 to 69.8 for the EHA and LDA, respectively. Following treatment with pyrantel, reduction in faecal egg counts was negative or $0 \%$. Deep amplicon sequencing of the isotype-1 $\beta$-tubulin gene identified a high frequency of resistance-associated SNPs at codon 167 in all three resistant isolates and in two additional clinical cases.

Conclusions: These data conclusively demonstrate multiple anthelmintic resistance in multiple independent isolates of A. caninum, strongly suggesting that this is an emerging problem in the USA. Furthermore, evidence suggest that these resistant hookworms originate from racing greyhound farms and kennels, though additional research is needed to confirm this.
\end{abstract}

Keywords: Ancylostoma caninum, Hookworms, Resistance, Anthelmintics, Canine health

\footnotetext{
*Correspondence: pdj38559@uga.edu

${ }^{1}$ Department of Infectious Diseases, College of Veterinary Medicine,

University of Georgia, Athens, GA 30602, USA

Full list of author information is available at the end of the article
} 


\section{Background}

The canine hookworm, Ancylostoma caninum, is the most prevalent and important intestinal nematode parasite of dogs in the USA [1]. A recent study evaluating over 39 million fecal samples from 2012-2018, showed evidence of a steady yearly increase in prevalence from 2015-2018, with an overall increase of 47\% [2]. Anthelmintic drugs approved for the treatment of A. caninum in the USA include, febantel, moxidectin, milbemycin oxime, fenbendazole and pyrantel. In registration studies, febantel, moxidectin and milbemycin oxime all demonstrated efficacy of $>99 \%$ [3-5], fenbendazole demonstrated efficacy of $>98 \%$ [6] and pyrantel demonstrated a somewhat variable efficacy, with a mean across studies of approximately $94 \%$, where more than half of those studies yielded $>99 \%$ [7]. Pathological consequences of hookworm infection include iron-deficiency anemia, hypoalbuminemia and enteritis, characterized by diarrhea that may contain fresh (hematochezia) or digested blood (melena) [8-10].

Hookworms are very successful parasites and one of the main reasons is the multiple routes by which they can infect their hosts. Ancylostoma caninum is transmitted by the transmammary route to newborn puppies [11], percutaneously [12], orally [9], or via ingestion of paratenic hosts, such as rodents [13] and insects [14]. Transmammary infection results from reactivation of arrested tissue-stage larvae in pregnant bitches, which then travel to the mammary glands, where they are passed in the colostrum and milk to newborn puppies for up to 18 days [15].

In puppies infected via skin penetration there is a blood-lung migration pathway [16, 17]. However, in older dogs, this pathway and developmental cycle is substantially modified; rather than the lungs, most of the larvae penetrate peripheral organs (somatic tissues) such as muscle (M.D. Little, unpublished observations) or gut wall [18], where they enter into an arrested state and are capable of surviving for several years [19].

An interesting biological feature of $A$. caninum infection is the phenomenon known as "larval leak", where arrested somatic larvae continuously migrate to the small intestine where they develop to the adult stage [ 9 , 19]. These cases are not associated with pregnancy and dogs with "larval leak" will chronically shed hookworm eggs, often in low numbers, with treatment only providing a temporary break of egg shedding, due to new reactivated hypobiotic larvae repopulating the gut and beginning a new round of egg shedding within a few weeks of treatment [16]. The actual mechanism responsible for this phenomenon is thought to be an immunological deficit; however, a specific cause has not been elucidated [20].
Because this larval reactivation is a well-described phenomenon, dogs presenting with recurrent hookworm infections are presumed to be suffering from this problem. Even though, no data are available to document the historical number of cases of recurrent hookworm infection in dogs, parasitologists at several veterinary colleges in the USA who we have communicated with, including our laboratory, have received increasing numbers of communications in the last 2-3 years. These cases are heavily overrepresented by greyhounds, but include many other breeds as well. The emergence of anthelmintic resistance in $A$. caninum would give a plausible explanation for these recent observations.

Parasitic strongylid nematodes have a number of genetic features, which favour the development of anthelmintic resistance, such as rapid rates of nucleotide sequence evolution and exceedingly large effective population sizes, leading to remarkably high levels of genetic diversity [21, 22]. Anthelmintic resistance is a heritable trait [23], and is defined as occurring 'when a greater frequency of individuals in a parasite population, usually affected by a dose or concentration of compound, are no longer affected, or a greater concentration of drug is required to reach a certain level of efficacy [24]. Ancylostoma caninum is the most common nematode parasite of greyhounds on breeding farms [25]; this high prevalence is likely a consequence of the unrestricted access to exercise runs made out of sand and dirt, which produces an ideal environment for the development and survival of the infective larvae [16]. To address the problem of nematode infections, the dogs on these breeding farms are subject to a very intense deworming protocol; puppies are often treated weekly with an anthelmintic until three months of age, then tri-weekly until sixth months of age, and then monthly for the rest of their breeding or racing lives [25]. This would present a very high drug selection pressure on the hookworm population on these farms and racing kennels.

In livestock, the intensive use and near complete reliance on anthelmintic drugs for control of nematode infections has led to high levels of anthelmintic resistance and multi-drug resistant (MDR) populations of nematodes on a global scale [26]. In contrast, anthelmintic resistance in $A$. caninum has developed much more slowly, with few cases reported, and until this year, only to pyrantel. The first report of pyrantel resistance was from New Zealand in a greyhound puppy that was imported from Australia [27], with several more cases subsequently diagnosed in Australia [28-32]. The issue of whether resistance is likely to become a problem in parasites of dogs has received relatively little attention, and when addressed, it has been viewed 
as an issue relating to the increased use of prophylactic helminth treatments in pets [33]. However, the epidemiology of nematode transmission on greyhound farms much more closely resembles the epidemiological conditions present on livestock farms, than to the epidemiological conditions present in a pet home environment. Consequently, it would not be surprising if anthelmintic resistance also were to become a common problem on greyhound farms. Interestingly, coincident with our investigations, a recent publication reported resistance to benzimidazoles and macrocyclic lactones in an isolate of A. caninum obtained from a greyhound $\operatorname{dog}$ [34]. The dog in that case presented to a veterinary clinic with a hookworm infection that was subsequently refractory to multiple treatments with fenbendazole.

Beyond the concerns for canine health, multiple-drug resistance in canine hookworms could present serious public health concerns, since $A$. caninum is zoonotic. Humans infected percutaneously may develop cutaneous larva migrans (CLM) [35]. Cases of eosinophilic enteritis [36], as well as patent infections have also been described [37].

Given the increasing frequency of reports by veterinarians that our laboratory has been receiving of recurrent hookworm infections that are poorly responsive to anthelmintics, it seemed likely that anthelmintic resistance had evolved in A. caninum. The aim of this study was to characterize several of these suspected resistant isolates using in vitro, genetic, and clinical testing.

\section{Methods}

\section{Parasite isolates}

Three fecal samples containing hookworm eggs were received from veterinarians who were treating cases of recurrent hookworm infections in canine patients. These three "suspected-resistant" isolates of $A$. caninum were designated Worthy, Lacy and Tara. Two additional fecal samples from $A$. caninum isolates from dogs with no history of anthelmintic treatments were also received. One designated ETCR, was previously cycled in the laboratory and confirmed as susceptible, and a second was acquired from a local dog shelter, which was confirmed as susceptible during the study. For the experimental infections, eggs recovered from fecal samples were placed onto NGM plates [38] and cultured for seven days to obtain third-stage infective larvae, which were used subsequently to orally infect purpose-bred research dogs (University of Georgia AUP \# A2017 10-016-Y1-A0).

In order to distinguish different passages and treatment events of the hookworm isolates, we established a naming convention as follows: name of the isolate followed by a number that corresponds to the number of passages the isolate has undergone. The letters $\mathrm{F}, \mathrm{P}$ and $\mathrm{M}$ after the dot correspond to any treatments applied with either fenbendazole, pyrantel or milbemycin oxime, respectively. The number preceding the letter indicates the passage in which this treatment took place. For example, Worthy 4.1F2P3M would correspond to the fourth passage of the Worthy isolate and treatment with fenbendazole in the first passage, treatment with pyrantel in the second passage and treatment with milbemycin oxime in the third passage. Available diagnostic and treatment histories of the dogs from which we obtained the hookworm isolates are as follows.

\section{Worthy}

Three-year-old greyhound, adopted December 10, 2016 from Florida and currently residing in Tennessee. Prior to adoption, the dog was treated with pyrantel and administered heartworm prophylaxis (not specified).

- January 11, 2017: New pet exam at University of Tennessee College of Veterinary Medicine Community Practice Clinic, fecal-positive for hookworms. Administered fenbendazole $(50 \mathrm{mg} / \mathrm{kg}$ ) daily for 10 days and started monthly Heartgard ${ }^{\circledR}$ Plus (Merck, Kenilworth, NJ, USA) (ivermectin/pyrantel).

- January 31, 2017: Fecal-positive for hookworms. Administered fenbendazole $(50 \mathrm{mg} / \mathrm{kg}$ ) daily for 10 days.

- February 21, 2017: Fecal-negative.

- April 20, 2017: Fecal-positive for hookworms, reporting many eggs seen. Administered fenbendazole $(50 \mathrm{mg} / \mathrm{kg})$ daily for 10 days.

- July 26, 2017: Administered fenbendazole $(50 \mathrm{mg} /$ $\mathrm{kg})$ daily for 10 days and switched from Heartgard ${ }^{\circledR}$ Plus (Merck) (ivermectin/pyrantel) to monthly Advantage Multi ${ }^{\circledR}$ (Bayer, Leverkusen, Germany) (imidacloprid/moxidectin).

- August 7, 2017: Administered fenbendazole (50 $\mathrm{mg} / \mathrm{kg}$ ) daily for 10 days.

- August 21, 2017: Fecal-positive for hookworms. Administered Advantage Multi ${ }^{\circledR}$ (Bayer, Leverkusen, Germany) (imidacloprid/moxidectin).

- September 21, 2017: Fecal-positive for hookworms. Administered Advantage Multi ${ }^{\circledR}$ (Bayer, Leverkusen, Germany) (imidacloprid/moxidectin).

- October 16, 2017: Fecal-positive for hookworms. Sample sent to the University of Georgia. Fecal egg count (FEC) of 160 eggs per gram (EPG).

- December 20, 2017: Research purpose-bred beagle was infected with 201 third-stage larvae. 


\section{Tara}

Adult miniature schnauzer breeding bitch from St. Augustine, Florida.

- Spring 2017: Fecal examination was positive for hookworm eggs. Adult dogs started on Drontal ${ }^{\circledR}$ Plus (Bayer, Leverkusen, Germany) (praziquantel/ pyrantel pamoate/febantel) once per month, with puppies receiving treatment at 2, 4, 6 and 8 weeks of age and then once per month afterwards. In addition, all dogs at this breeding kennel received Heartgard ${ }^{\circledR}$ Plus (Merck) (ivermectin/pyrantel) monthly. Therefore, all dogs were being treated twice monthly with pyrantel and once monthly with febantel.

- November 2017: Fecal examination positive for hookworms and sample sent to UGA. FEC of 100 EPG.

- December 20, 2017: Research purpose-bred beagle was infected with 250 third-stage larvae.

\section{Lacy}

Adult hound mix from Griffin, Georgia.

- Mid October-Mid November 2017: Treated twice, three weeks apart with a compounded combination of pyrantel, praziquantel and mebendazole.

- December 11, 2017: Dog was treated with a compounded combination of praziquantel, pyrantel, and oxantel.

- December 13 and December 15, 2017: Treated with pyrantel.

- December 16, 2017: Adult hookworm specimens were found whilst taking rectal temperature and hookworm eggs were present in feces. Treated with fenbendazole for 3 days (December 16-18, 2017).

- December 18, 2017: Fecal sample submitted to UGA containing live adult worms and eggs present in the feces. No FEC was performed.

- January 25, 2018: Research purpose-bred beagle was infected with 250 third-stage larvae.

\section{ETCR}

Susceptible laboratory isolate: from a naturally infected adult dog residing in Cumberland County, Tennessee, in June 2016 with a history of no anthelmintic treatments ever being given. This isolate had subsequent passages in research purpose-bred beagles and a sample was received at UGA on October 17, 2017, with further propagation in a research purpose-bred beagle.

\section{Barrow}

Susceptible laboratory isolate: a pooled fecal sample from an unknown number of naturally-infected adult shelter dogs residing in Barrow County, Georgia with no history of anthelmintic treatments. Sample was received at UGA on March 13, 2018. Research purpose-bred beagle was infected with 250 third-stage larvae on April 17, 2018.

\section{In vitro assays}

Fresh feces from laboratory beagles infected with the Worthy, Tara, Lacy, ETCR and Barrow isolates were collected and made into a slurry with water, followed by filtration through $425 \mu \mathrm{m}$ and $180 \mu \mathrm{m}$ sieves and then again through $85 \mu \mathrm{m}$ and $30 \mu \mathrm{m}$ nylon filters. The fecal material containing the eggs was then rinsed from the $30 \mu \mathrm{m}$ filter with distilled water and reduced to a volume of 10-15 ml. This was then layered on top of saturated sucrose and centrifuged at $1372 \times g$ for $7 \mathrm{~min}$ at $4{ }^{\circ} \mathrm{C}$. Following centrifugation, eggs were recovered, rinsed with distilled water through a $20 \mu \mathrm{m}$ sieve, transferred to a tube and then the volume was adjusted to yield 50-60 eggs per $20 \mu \mathrm{l}$ using distilled water.

\section{Egg hatch assay (EHA)}

Fresh feces containing undeveloped eggs were used, as partial egg development may affect the dose response [39]. Assays were performed using both agar and liquidbased methods with no significant difference detected between methods. Agar-based assays were performed using 96-well plates using a previously described agarmatrix technique [40] with minor modification. Liquidbased assays were also performed using a 96-well plate format [41] with minor modifications. A stock solution of $80 \mathrm{mM}$ of thiabendazole (Sigma-Aldrich, St. Louis, MO, USA) was prepared using 100\% dimethyl sulfoxide (DMSO, Sigma-Aldrich, St. Louis, MO, USA) and then was serially diluted using distilled water to produce 10 final concentrations ranging from 36 to $0.001125 \mu \mathrm{M}$ in $1 \%$ DMSO. The first two wells of each row were negative controls containing only $0.5 \%$ DMSO for the agar plates and 1\% DMSO for the liquid-based plates and wells 3-12 contained increasing concentrations of thiabendazole. Agar-based assay plates were prepared by adding $70 \mu \mathrm{l}$ of $2 \%$ Agar (Bacto Agar, VWR, Becton Dickinson Sparks, MD, USA) and $70 \mu \mathrm{l}$ of thiabendazole solution to each well. Liquid-based plates were prepared by just adding $100 \mu \mathrm{l}$ of thiabendazole solution to each well with no agar. Agar plates were sealed with Parafilm (Bemis NA, Neenah, WI, USA) and stored in the refrigerator at $4{ }^{\circ} \mathrm{C}$ for a maximum of one week. Prior to performing the assays, plates were removed from the refrigerator and permitted to reach room temperature. Approximately 
50-60 eggs in a volume of $10 \mu \mathrm{l}$ were then added to each well. Plates were incubated for $48 \mathrm{~h}$ at $25{ }^{\circ} \mathrm{C}$ and assays were terminated by adding $20 \mu \mathrm{l}$ of $10 \%$ Lugols iodine to all wells. Numbers of eggs and larvae in each well were counted and hatching was corrected for the average hatching rate in the control wells. The initial assays using ETCR, ETCR 1.0, Barrow, Tara, Lacy, Worthy, Worthy $1.1 \mathrm{~F}$ and Worthy $2.1 \mathrm{~F}$ were performed singly with each thiabendazole concentration tested in triplicate. In order to improve the precision of our measurement of $\mathrm{IC}_{50}$ and reduce the width of the $95 \%$ confidence intervals, we repeated the assays using three biological replicates of Barrow 1.0 and Worthy 4.1F3P, with three technical replicates per concentration in each assay.

\section{Larval development assay (LDA)}

Larval development assays were performed initially using DrenchRite $^{\circledR}$ LDA (Microbial Screening Technologies, Armidale, New South Wales, Australia) assay plates [42]. The DrenchRite ${ }^{\circledR}$ LDA evaluates resistance to benzimidazoles, macrocyclic lactones and levamisole using the drugs, thiabendazole, ivermectin aglycone and levamisole, respectively. Subsequently, LDA plates were prepared using only ivermectin aglycone. The three-drug plates had concentrations of ivermectin aglycone ranging between $0.97-10,000 \mathrm{nM}$ and the ivermectin aglycone-only plates had concentrations ranging between 1.9-1000 nM. After isolating the eggs as described for the EHA, $90 \mu \mathrm{l} / \mathrm{ml}$ of amphotericin B $(250 \mu \mathrm{g} / \mathrm{ml}$, supplied by Microbial Screening Technologies) were added and $20 \mu$ l containing approximately 50-70 eggs were dispensed into each well. Assay plates were sealed with Parafilm and incubated at $25^{\circ} \mathrm{C}$. After $24 \mathrm{~h}, 20 \mu \mathrm{l}$ of nutritive media, composed of $0.87 \%$ Earle's balanced salts, (SigmaAldrich, St. Louis, MO, USA), 1\% yeast extract (BD Difco, VWR, Becton Dickinson Sparks, MD, USA), 0.76\% NaCl (Sigma-Aldrich, St. Louis, MO, USA), with an addition of $1 \%$ E. coli OP50, were added to each well. The plates were resealed and incubated for 6 additional days, after which the assays were terminated by adding $20 \mu$ l of $50 \%$ Lugols iodine to all wells. The contents of each well were transferred to a clean 96-flat well plate and all eggs and larvae in each well were counted using an inverted microscope as previously described [43]. Development to L3 was corrected for all drug wells based on the average development in the control wells. The LDA does not evaluate pyrantel, which is the other anthelmintic approved for the treatment of hookworms of dogs in the USA. However, levamisole, which is used in the DrenchRite ${ }^{\circledR}$ plate, has a similar mechanism of action to pyrantel [44]. The initials assays performed with ETCR 1.0, Lacy and Worthy 1.0 were performed singly with each ivermectin concentration tested in duplicate. In order to improve the precision of our measurement of $\mathrm{IC}_{50}$ and reduce the width of the $95 \%$ confidence intervals, we repeated the assays using three biological replicates of laboratory isolates Barrow 1.0 and Worthy 4.1F3P, with two technical replicates per concentration in each assay.

\section{In vivo measurements}

One laboratory dog infected with the initial Tara isolate (first passage) and two dogs infected with larvae from the second passage of the Worthy isolate (Worthy 2.1F), were treated orally with pyrantel $\left(10 \mathrm{mg} / \mathrm{kg}\right.$, Strongid ${ }^{\circledR}$, Parsippany-Troy Hills, NJ, USA). Reductions in fecal egg counts (FEC) were measured at day 10 for the Tara isolate and at day 13 for the Worthy isolate. The average of the FEC from the two dogs infected with the Worthy isolate was used for the reduction calculation. All FEC were performed in triplicate using the Mini-FLOTAC (University of Naples Federico II, Naples, Italy) procedure with a detection threshold of 5 EPG $[45,46]$, adding $2 \mathrm{~g}$ of feces to $18 \mathrm{ml}$ of sodium nitrate $\left(\right.$ Feca-Med ${ }^{\circledR}$, Vedco, Inc. St. Joseph; MO, USA, specific gravity $=1.2$ ). Fecal egg count reduction was calculated using the following formula: (Pre-treatment FEC-Post-treatment FEC)/(Pre-treatment FEC) $\times 100$. For the pre-treatment FEC, we used the 2-day mean of the day prior to treatment and the day of treatment or the average of the two days before treatment if FEC were not performed on the day of treatment.

\section{Ancylostoma caninum isotype-1 $\beta$-tubulin deep amplicon sequencing}

DNA was extracted from pools of eggs, third-stage larvae or adults using a previously described lysis protocol [47]. Deep amplicon sequencing assays were developed to determine the frequency of non-synonymous single nucleotide polymorphisms (SNP) at codons 167, 198 and 200 of the $A$. caninum isotype- $1 \beta$-tubulin gene. The approach and methods were as previously described for ruminant trichostrongylid nematodes except for the primer design [48]. The presence of a large intron between exons 4 and 5 (1217 bp in reference sequence (GenBank: DQ459314.1) meant that a single amplicon encompassing the three codons of interest would be too long for reliable Illumina sequencing. Consequently, primers were designed to amplify two separate regions of the $A$. caninum isotype- $1 \beta$-tubulin gene; a $293 \mathrm{bp}$ fragment between exons 3 and 4 encompassing codon 167 and a $340 \mathrm{bp}$ fragment between exons 5 and 6 encompassing codons 198 and 200 (Table 1).

Using these primers, adapted primers suitable for Illumina next-generation sequencing were designed as previously described [48]. The following PCR conditions were used to generate both fragments appropriate for sequencing: $5 \mu \mathrm{l}$ of $5 \times$ NEB Q5 Reaction Buffer (New England 
Biolabs Ltd, Ipswich, MA, USA), $0.5 \mu \mathrm{l}$ of $10 \mathrm{mM}$ dNTPs, $1.25 \mu \mathrm{l}$ of $10 \mu \mathrm{M}$ Forward primer mixture, $1.25 \mu \mathrm{l}$ of 10 $\mu \mathrm{M}$ Reverse primer mixture, $0.25 \mu \mathrm{l}$ of NEB Q 5 polymerase, $13.75 \mu \mathrm{l}$ of molecular grade water and $3 \mu \mathrm{l}$ of DNA lysate. The thermocycling parameters were $98^{\circ} \mathrm{C}$ for $30 \mathrm{~s}$, followed by 45 cycles of $98^{\circ} \mathrm{C}$ for $10 \mathrm{~s}, 65^{\circ} \mathrm{C}$ for $15 \mathrm{~s}$, and $72{ }^{\circ} \mathrm{C}$ for $25 \mathrm{~s}$, followed by $72{ }^{\circ} \mathrm{C}$ for $2 \mathrm{~min}$. Samples were purified and barcoded primers added following the protocols outlined in Avramenko et al. [48]. Library preparation was as previously described and library sequencing performed using the Illumina MiSeq platform with the $2 \times 250$ v2 Reagent Kit (Illumina Inc., San Diego, CA, USA) [47]. The average read depth was $\sim 14,000$ for each sample fragment, ranging between 10,000 and 19,000 reads. Sequence analysis was performed following the bioinformatic pipeline outlined in Avramenko et al. [48]. Generated sequences were compared against a susceptible genotype $A$. caninum isotype-1 $\beta$-tubulin reference sequence (GenBank: DQ459314.1). Only observed variants resulting in non-synonymous changes at codons 167, 198 and 200 that are known to be associated with benzimidazole resistance in other strongylid nematodes are reported. The isolates examined were ETCR, Barrow, Worthy, Worthy 1.1F, Worthy 2.1F, Tara, Tara 1.1F and Lacy. Additionally, two clinical samples with a history of recurrent infections despite repeated anthelmintic treatments were included; Fame Taker (retired racing greyhound residing in Georgia) and Dolores (laboratory mix, Worthy's housemate companion).

\section{Ancylostoma caninum ITS-2 rDNA deep amplicon sequencing}

In order to confirm the hookworm species represented in the various samples, we used an ITS-2 rDNA deep amplicon sequencing assay [47]. This method is capable of discriminating between different nematode species based upon the sequence identity of the ITS-2 region of the rDNA. The samples were prepared and sequenced as described in Avramenko et al. [47] and analysed with the bioinformatic pipeline described in Avramenko et al. [49]. Several A. caninum and A. braziliense ITS-2 sequences were added to the analysis database for the purposes of this analysis (GenBank: DQ438050-DQ438054,
DQ438060-DQ438062,

DQ438065-DQ438067, AB751614-AB751616, DQ438072-DQ438079).

\section{Data analyses}

All dose-response analyses were performed after logtransformation of the drug concentrations and constraining the bottom value to zero. Data were then fitted to a four-parameter non-linear regression algorithm with variable slope (GraphPad Prism ${ }^{\circledR}$ version 8.0, GraphPad Software, San Diego, CA, USA). The $\mathrm{IC}_{50}$ values, which represent the concentration of drug required to inhibit hatching (EHA) or development to the third larval stage (LDA) by $50 \%$ of the maximal response and corresponding resistance ratios $\left(\mathrm{IC}_{50}\right.$ resistant isolate $/ \mathrm{IC}_{50}$ susceptible isolate) were calculated.

\section{Results}

Adult worms recovered from a hookworm case confirmed as being multiple-drug resistant in this study were identified using morphological criteria as being A. caninum (not shown). Additionally, all samples analyzed were assessed with an ITS-2 deep amplicon sequencing assay as described in the methods section, confirming that they were $A$. caninum based upon sequence identity of the generated amplicons. This assay uses a taxonomy-based approach to assess the identity of generated amplicons, based upon a provided reference database. Compared to an example $A$. caninum reference sequence (GenBank: AB751614), generated ITS-2 amplicons had between 96.9-100\% sequence identity compared to the reference. Additionally, compared to an example $A$. braziliense reference sequence (GenBank: DQ438050), generated ITS-2 amplicons had $80.6-82.7 \%$ sequence identity, further supporting classification as $A$. caninum rather than $A$. braziliense.

\section{In vitro assays}

The EHA yielded high $R^{2}$ values for the dose response and provided excellent discrimination between the susceptible and resistant isolates. In the initial testing using samples from the original source dogs, the resistance ratios for Lacy, Tara and Worthy, as compared to the ETCR susceptible isolate were $10.9,11.8$ and 14.5 , respectively,

Table 1 Ancylostoma spp. isotype-1 $\beta$-tubulin primers

\begin{tabular}{|c|c|c|c|c|}
\hline Primer & Sequence $\left(5^{\prime}-3^{\prime}\right)$ & Length (bp) & Forward/reverse & Codons \\
\hline ACB1_167_F & GGYGCAGGAAACAACTG & 17 & Forward & 167 \\
\hline ACB1_167_R & CTTTGGTGAGGGGACAACA & 19 & Reverse & 167 \\
\hline ACB1_200_F & GTRGTGGAGCCATACAATGC & 20 & Forward & 198,200 \\
\hline ACB1_200_R & GGCATGAAGAAGTGAAGACGT & 21 & Reverse & 198,200 \\
\hline
\end{tabular}



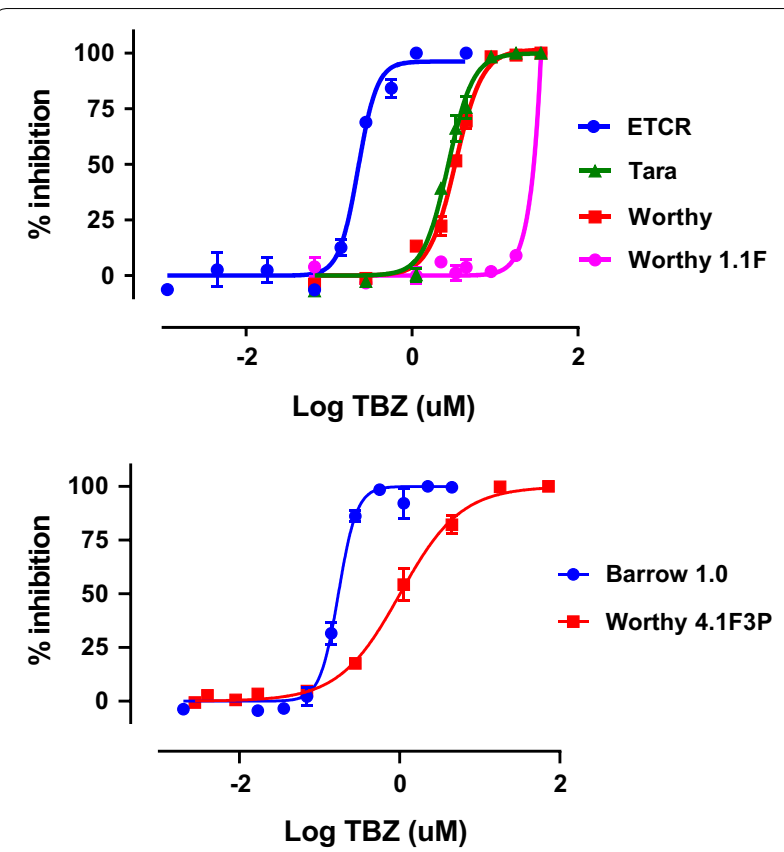

Fig. 1 Dose-response curves for the Egg Hatch Assay. Initial assays were performed singly using ETCR, Tara, Worthy and Worthy 1.1F. Subsequent assays were performed in triplicate using the Barrow 1.0 and Worthy 4.1F3P isolates with three replicates per concentration. Curves were generated using the variable slope nonlinear regression model analysis in GraphPad 8

indicating that these isolates had a high level of resistance to benzimidazole anthelmintics (Fig. 1, Table 2).

Interestingly, a second EHA performed on the first passage of the Worthy isolate 13 days following treatment with fenbendazole demonstrated a large shift in dose response as compared to the original test. The $\mathrm{IC}_{50}$ for Worthy increased more than 10 -fold, from $3.35 \mu \mathrm{M}$ to greater than $36 \mu \mathrm{M}$, yielding a resistance ratio of greater than 100 . An accurate $\mathrm{IC}_{50}$ could not be calculated since $36 \mu \mathrm{M}$ was the highest concentration tested. Subsequent testing using the laboratory isolates Barrow 1.0 and Worthy 4.1F3P, also yielded high $R^{2}$ values, but the slope of the dose response for Worthy 4.1F3P had changed as compared to previous assays and this impacted the calculated value for $\mathrm{IC}_{50}$. Although the $\mathrm{IC}_{50}$ for the susceptible Barrow 1.0 isolate $(0.17 \mu \mathrm{M})$ was similar to that of the susceptible ETCR isolate, the $\mathrm{IC}_{50}$ for Worthy 4.1F3P decreased to $1.01 \mu \mathrm{M}$; this yielded a resistance ratio of only 6 . In comparison, the resistance ratio for the $\mathrm{IC}_{95}$ was 41.25 ; this difference from the resistance ratio for the $\mathrm{IC}_{50}$ is largely due to the difference in the slope of the dose response (Fig. 1, Table 2).

The LDA failed to provide good discrimination between the benzimidazole-susceptible and -resistant isolates, yielding resistance ratios of less than 2.0 (Table 2). Using levamisole, the LDA yielded dose response curves with low $R^{2}$; this prevented both the calculation of accurate $\mathrm{IC}_{50}$ values and any useful discrimination between pyrantel-susceptible and -resistant isolates (data not shown). In contrast, ivermectin aglycone, yielded strong discrimination for detecting resistance to macrocyclic lactones, with resistance ratios of 5.5 and 63.2 for Lacy and Worthy 1.0, respectively (Fig. 2, Table 3).

Assays performed using multiple biological replicates of Barrow 1.0 and Worthy 4.1F3P yielded high $R^{2}$ values for the dose response and a resistance ratio of 69.8 , which

Table $2 I_{50}$ data for benzimidazoles in Ancylostoma caninum isolates

\begin{tabular}{|c|c|c|c|c|c|c|}
\hline Isolate & $\mathrm{EHA}(\mu \mathrm{M}) \mathrm{IC}_{50}(95 \% \mathrm{Cl})$ & $\mathrm{EHA} \mathrm{IC}_{50} \mathrm{RR}$ & $\operatorname{LDA}(\mu \mathrm{M}) \mathrm{IC}_{50}$ & $\mathrm{LDA} \mathrm{IC}_{50} \mathrm{RR}$ & $\mathrm{EHA}(\mu \mathrm{M}) \mathrm{IC}_{95}(95 \% \mathrm{Cl})$ & $\mathrm{EHA} \mathrm{IC}_{95} \mathrm{RR}$ \\
\hline ETCR & 0.23 & & - & & 0.49 & \\
\hline ETCR 1.0 & 0.25 & & 0.07 & & 1.13 & \\
\hline Barrow & 0.24 & & - & & 3.46 & \\
\hline Tara & 2.73 & 11.8 & 0.12 & 1.7 & 7.60 & 15.5 \\
\hline Lacy & 2.51 & 10.9 & 0.13 & 1.8 & 31.14 & 63.6 \\
\hline Worthy & 3.35 & 14.5 & - & & 10.07 & 20.6 \\
\hline Worthy $1.1 \mathrm{~F}$ & $>36$ & $>100$ & - & & $>36$ & $>70$ \\
\hline Worthy $2.1 \mathrm{~F}$ & 2.65 & 11.5 & - & & $>36$ & $>70$ \\
\hline Barrow 1.0 & $0.17(0.16-0.19)$ & - & - & & $0.36(0.28-0.46)$ & \\
\hline Worthy 4.1F3P & $1.02(0.92-1.12)$ & 6.0 & - & & $14.85(9.96-23.22)$ & 41.3 \\
\hline
\end{tabular}

Notes: ETCR was the susceptible isolate used for calculating resistance ratios in the initial assays and Barrow 1.0 was used for the EHA and ETCR 1.0 for the LDA in subsequent assays. Initial assays were performed singly using ETCR, ETCR 1.0, Barrow, Tara, Lacy, Worthy, Worthy $1.1 \mathrm{~F}$ and Worthy $2.1 \mathrm{~F}$ and subsequent assays were performed in triplicate using Barrow 1.0 and Worthy 4.1F3P, in order to improve the precision of the estimate and reduce the width of the $95 \%$ confidence intervals (CI). The values for Barrow 1.0 and Worthy 4.1F3P represent the mean $\mathrm{IC}_{50}$ of three biological replicate assays, with each thiabendazole concentration measured in triplicate. IC $\mathrm{C}_{95}$ values were also calculated for the EHA. Resistance ratios (RR) were calculated as IC $\mathrm{C}_{50 / 95}$ resistant isolate/IC $\mathrm{C}_{50 / 95}$ susceptible isolate; $\mathrm{RR}$ are not provided for the susceptible isolates or where assays were not performed, as this value has no relevance in those instances 

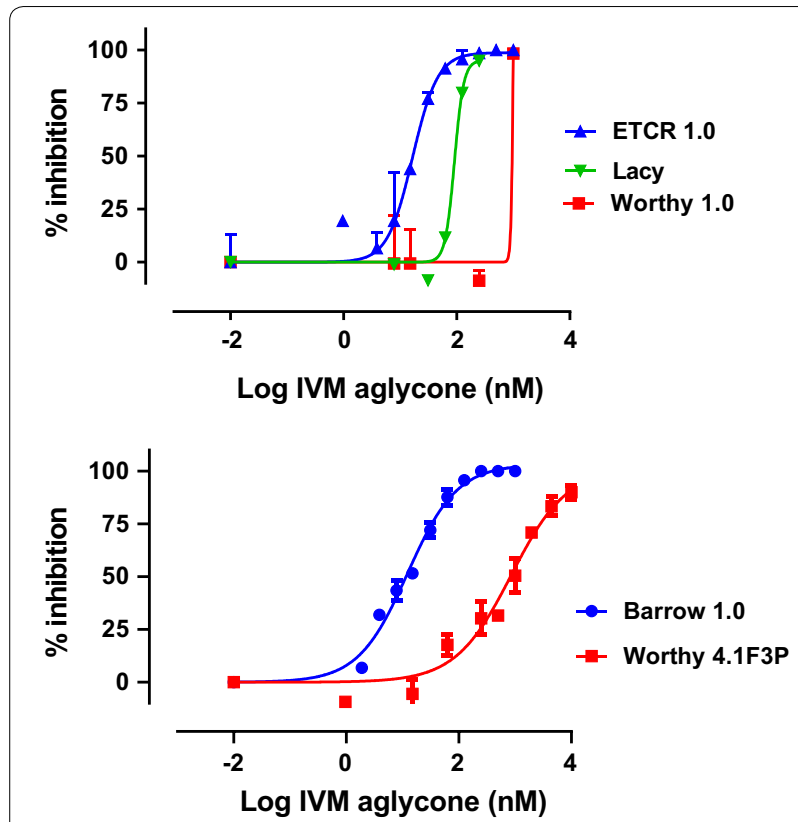

Fig. 2 Dose-response curves for the Larval Development Assay. Initial assays were performed singly using ETCR 1.0 Lacy and Worthy 1.0. Subsequent assays were performed in triplicate using Barrow 1.0 and Worthy 4.1F3P isolates with two replicates per concentration. Curves were generated using the variable slope nonlinear regression model analysis in GraphPad 8

Table 3 DrenchRite LDA dose response data for macrocyclic lactones in Ancylostoma caninum isolates

\begin{tabular}{llll}
\hline ssolate & LDA IC $_{50}(\mathrm{nM})(95 \% \mathrm{Cl})$ & $R^{2}$ & LDA RR \\
\hline ETCR 1.0 & 16.62 & 0.93 & \\
Lacy & 91.53 & 0.53 & 5.5 \\
Worthy 1.0 & 1052 & 0.45 & 63.2 \\
Barrow 1.0 & $12.31(10.42-14.70)$ & 0.98 & \\
Worthy 4.1F3P & $859(411.3-3426)$ & 0.92 & 69.8 \\
\hline
\end{tabular}

Notes: Initial assays were performed singly using ETCR 1.0, Lacy and Worthy 1.0 and subsequent assays were performed in triplicate using Barrow 1.0 and Worthy 4.1F3P, in order to improve the precision of the estimate and reduce the width of the $95 \%$ confidence intervals $(\mathrm{Cl})$. In all assays each ivermectin aglycone concentration was measured in duplicate. Resistance ratios (RR) were calculated as $I C_{50}$ resistant isolate/IC $C_{50}$ susceptible isolate; $R R$ are not provided for the susceptible isolates, as this value has no relevance

Abbreviations: LDA, larval development assay

was quite similar to the resistance ratio for the macrocyclic lactones in the earlier assays (Fig. 2, Table 3).

\section{In vivo measurements}

Reductions in FEC were measured on the Tara and Worthy isolates following treatment with pyrantel. For both isolates there was essentially no reduction in FEC following treatment with pyrantel; FEC in Tara actually increased (negative reduction) and FEC in

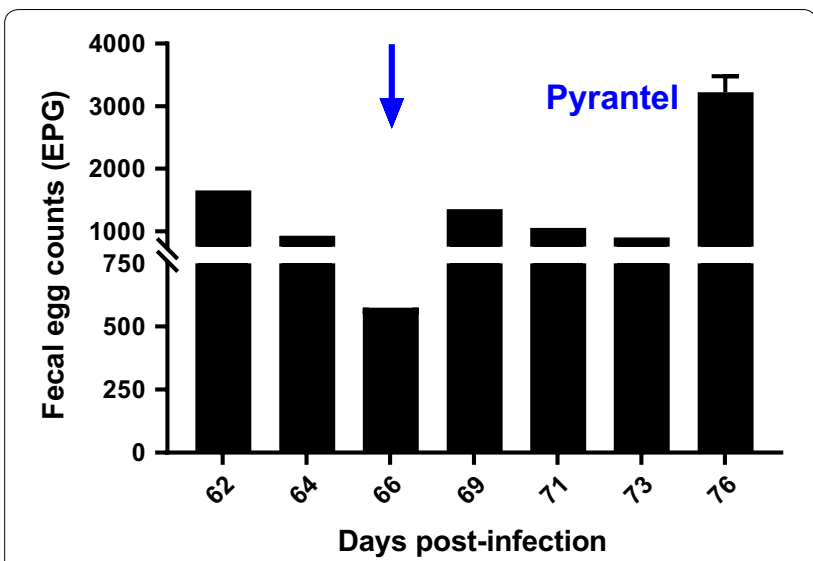

Fig. 3 Fecal egg counts (FEC) over the course of infection of a dog infected with the Tara isolate. Treatment with pyrantel was administered on day 66 (23 February 2018) and post-treatment FEC was performed on day 10 post-treatment

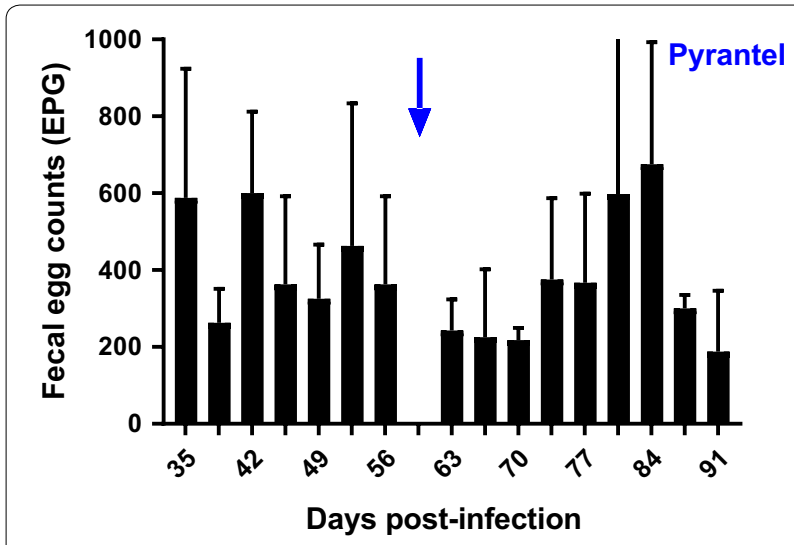

Fig. 4 Average of fecal egg counts (FEC) over the course of infection of two dogs infected with larvae from the second passage of the Worthy isolate, with a treatment event with fenbendazole on the first passage (Worthy 2.1F). Treatment with pyrantel was administered on day 55 (25 October 2018) and post-treatment FEC was performed on day 13 post-treatment

Worthy remained unchanged (3\% reduction) (Figs. 3, 4, respectively).

\section{Benzimidazole resistance-associated SNP frequencies determined by deep amplicon sequencing}

Two PCR amplicons, encompassing codons 167 and $198 / 200$ of the isotype $1 \beta$-tubulin gene respectively, were sequenced at depth to investigate the presence and determine the frequency of SNP associated with benzimidazole resistance in ruminant trichostrongylid species (Table 4).

SNP associated with benzimidazole resistance were only seen at position 167. All three phenotypically 
Table 4 Single nucleotide polymorphism frequencies for A. caninum isolates at the three different codons associated with resistance to benzimidazoles

\begin{tabular}{|c|c|c|c|c|c|}
\hline Isolate/Patient & BZ phenotype (S/R) & Sample sequenced & $\begin{array}{l}\text { F167Y } \\
\text { Freq (\%) }\end{array}$ & $\begin{array}{l}\text { E198A } \\
\text { Freq (\%) }\end{array}$ & $\begin{array}{l}\text { F200Y } \\
\text { Freq (\%) }\end{array}$ \\
\hline ETCR & S & 250 eggs & 0 & 0 & 0 \\
\hline ETCR & $S$ & 300 L3 & 8.8 & 0 & 0 \\
\hline Barrow & $S$ & $250\llcorner 3$ & 1.2 & 0 & 0 \\
\hline Worthy & $\mathrm{R}$ & L3 & 92.2 & 0 & 0 \\
\hline Worthy $1.1 \mathrm{~F}$ & $\mathrm{R}$ & $300\llcorner 3$ & 87.6 & 0 & 0 \\
\hline Worthy $2.1 \mathrm{~F}$ & $\mathrm{R}$ & $100 \mathrm{~L} 3$ & 94.5 & 0 & 0 \\
\hline Tara & $\mathrm{R}$ & 375 eggs & 12.7 & 0 & 0 \\
\hline Tara 1.1F & $\mathrm{R}$ & $250 \mathrm{~L} 3$ & 50.9 & 0 & 0 \\
\hline Lacy & $\mathrm{R}$ & Single adult & 47.4 & 0 & 0 \\
\hline Lacy & $\mathrm{R}$ & Single adult & 52.9 & 0 & 0 \\
\hline Lacy & $\mathrm{R}$ & Single adult & 46.0 & 0 & 0 \\
\hline Lacy & $\mathrm{R}$ & Eggs & 99.7 & 0 & 0 \\
\hline Fame Taker & $\mathrm{R}$ & $350 \mathrm{L3}$ & 90.7 & 0 & 0 \\
\hline $\begin{array}{l}\text { Dolores (Worthy house com- } \\
\text { panion) }\end{array}$ & $\mathrm{R}$ & 300 L3 & 88.9 & 0 & 0 \\
\hline
\end{tabular}

Abbreviations: BZ, benzimidazoles; Freq, frequency; L3, third-stage larvae; S/R, susceptible/resistant

resistant isolates had a high frequency of the benzimidazole resistance associated F167Y (TTC > TAC) SNP in the samples tested, ranging from $13 \%$ to almost $100 \%$ (Table 4). In the samples from the susceptible isolates, the allele frequencies were $0 \%, 1 \%$ and $9 \%$ (Table 4). In the Tara isolate, following a single treatment with fenbendazole the SNP frequency increased from $13 \%$ to $51 \%$. For the Lacy isolate, the adults that were expelled after treatment with fenbendazole had allele frequencies of around 50\% indicating these worms were heterozygous for the SNP, whereas the eggs recovered from the same feces as the adults had SNP frequencies close to $100 \%$. For the clinical cases Fame taker and Dolores, the SNP frequency was around $90 \%$.

\section{Discussion}

In this study, we conclusively demonstrate for the first time the presence of multiple drug resistance to benzimidazoles, macrocyclic lactones and pyrantel in A. caninum. Coincident with our studies, a separate recent study reported resistance to benzimidazoles and macrocyclic lactones in A. caninum recovered from a greyhound dog [34]. The origins of these resistant hookworms remain to be determined; however, evidence suggests that they originated from racing greyhound farms. Ancylostoma caninum is the most prevalent parasitic nematode in racing greyhounds $[50,51]$ and this is attributed to the near constant exposure of these dogs to infective third-stage larvae in the sand/dirt exercise run/pens [25]. Racing greyhounds are also treated extremely frequently with multiple different anthelmintics throughout their lives [25]. The intervals between these treatments often are less than the pre-patent period for hookworms. This high intensity of treatment will minimize the amount of refugia (parasite life stages that are not exposed to anthelmintic treatment). Consequently, any worms surviving treatment will have a large reproductive advantage and will rapidly increase in frequency [52]. This combination of factors is known to place heavy selection pressure for drug resistance [24] and is very similar to the epidemiological factors that have led to high levels of multiple-drug resistance in nematodes of sheep and goats, worldwide. The EHA is an in vitro bioassay used for detecting resistance to benzimidazole anthelmintics [53]. Based on the ovicidal properties of the benzimidazole drug class [54], this assay has been used successfully to detect resistance against benzimidazoles in multiple nematode parasites of livestock [55-57]. Additionally, the EHA was assessed in A. caninum [40] and used to evaluate drug susceptibility/resistance to benzimidazoles in the human hookworm, Necator americanus [40, 58, 59]. The $\mathrm{IC}_{50}$ values we measured for the two susceptible isolates we tested were very similar to that previously reported for A. caninum [40], but in the resistant isolates, there was a clear shift to the right in the dose-response with resistance ratios greater than 6.0 in all isolates tested. Interestingly, when the EHA was repeated on parasite eggs collected from the resistant Worthy 1.0 isolate soon after treatment with fenbendazole, the right shift in 
the dose response increased dramatically, producing a resistance ratio of greater than 100 . Given that the high $\beta$-tubulin SNP frequencies measured for Worthy, had no significant change in the SNP frequencies in the before and after treatment samples, this dramatic increase in $\mathrm{IC}_{50}$ and resistance ratio suggests that the treatment triggered the induction of another resistance mechanism(s). The fact that the allele frequency did not change and the increase in the levels of resistance was only temporary suggests that was not due to heterogeneity, but instead a change in the parasite population, otherwise, it would have been a permanent change. However, this high level of induced resistance was only temporary, as testing of the same isolate on the second passage produced $\mathrm{IC}_{50}$ values similar to the original Worthy isolate prior to fenbendazole treatment. Nevertheless, these observations demand further study. Overall, these data demonstrate clearly that the EHA is able to effectively discriminate between benzimidazole-susceptible and -resistant isolates and that the isolates tested have high levels of benzimidazole resistance.

The LDA is a commonly used in vitro bioassay used for detecting resistance to multiple different classes of anthelmintics in gastrointestinal (GI) nematode parasites of sheep and goats $[42,60,61]$. The LDA is based on the ability of anthelmintics to prevent free-living pre-parasitic nematode stages from developing to the infective third-larval stage (L3) [62]. Testing the LDA using multiple isolates of $A$. caninum, both multiple-drug resistant and susceptible, we found the LDA to provide excellent discrimination between our susceptible and resistant isolates for the macrocyclic lactones, but did not provide useful levels of discrimination for benzimidazoles, or for pyrantel. The poor discrimination for resistance to benzimidazoles was similar to that recently reported for $A$. caninum [34]. Thus, unlike for GI nematodes of sheep where the LDA provides good discrimination for multiple drug classes, when used with A. caninum, the LDA appears only useful for measuring resistance to macrocyclic lactone drugs. This finding builds on previous works demonstrating that in vitro bioassays used for detection of anthelmintic resistance in parasitic nematodes are highly species-specific and drug class-specific in their ability to provide useful levels of discrimination between susceptible and resistant isolates $[43,57,63]$.

Interestingly, we found a wide range in the level of resistance in the two resistant isolates we tested and these differences seem to correlate with the clinical case histories of the source dogs prior to our receipt of the samples. The $\mathrm{IC}_{50}$ for the first passage of the Worthy isolate yielded a resistance ratio of 63.2, which is more than 11 times greater than the resistance ratio of 5.5 that we measured for Lacy. As noted in the clinical case histories, there was no history of recent use of macrocyclic lactones in Lacy, whereas Worthy had received three consecutive monthly treatments with moxidectin (Advantage Multi ${ }^{\circledR}$, Bayer, Leverkusen, Germany) just prior to our receipt of the sample. Furthermore, at the time the LDA data were collected, the Worthy isolate had not received treatment with a macrocyclic lactone drug after being established in the laboratory. This difference in clinical history likely is relevant for several reasons. First, to the best of our knowledge, greyhound farms and kennels have been administering ivermectin for parasite control for decades, but did not begin using moxidectin until very recently. Thus, it is unlikely that any of the dogs infected with the resistant isolates evaluated in this study were treated with moxidectin prior to adoption. Secondly, moxidectin is considerably more potent than ivermectin against many nematodes [64]. In $H$. contortus, ivermectin-resistant worms that are naïve to moxidectin are typically killed at very high efficacy following administration of moxidectin $[65,66]$; however, once moxidectin is used regularly in an ivermectin-resistant population, resistance to moxidectin can develop rapidly [61]. A study investigating the emergence of moxidectin resistance in $H$. contortus found that a farm naïve to moxidectin but with ivermectin resistance had an LDA resistance ratio of 5.3, whereas farms with resistance to moxidectin had resistance ratios of 32-128, which is 6-24-fold higher [61]. These similarities in the $A$. caninum and $H$. contortus data suggest that the resistant hookworms originating with the greyhounds and now spreading into the pet population have a clinically relevant level of resistance to macrocyclic lactones even without further selection, such as those infecting Lacy. However, as evidenced by the data from Worthy, additional selection with moxidectin can rapidly lead to very high levels of field-derived resistance.

The other recent report of resistance in A. caninum [34] also used the LDA to measure resistance to macrocyclic lactones; however, the data of the two studies are dramatically different. The $\mathrm{IC}_{50}$ and corresponding resistance ratio we measured in $A$. caninum for both macrocyclicresistant and -susceptible isolates were fairly comparable to those previously reported for $H$. contortus [61]. However, Kitchen et al. [34] reported values that are vastly different, both in terms of $\mathrm{IC}_{50}$ level and in magnitude of resistance ratio. The $\mathrm{IC}_{50}$ reported for their resistant isolate was lower than what we measured in our susceptible isolate and the $\mathrm{IC}_{50}$ reported for their susceptible isolate was at pM levels, almost 5000-fold lower than what we measured. This yielded resistance ratio of greater than 1000; a level that is greater than what has been reported, even in the most resistant Haemonchus isolates. Given the available clinical histories, the resistant isolate they studied was likely similar to the Lacy isolate, with little 
to no previous exposure to moxidectin. We measured a 5.5 resistance ratio for the Lacy isolate, thus their analyses demonstrated a resistance ratio more than 200 times greater than what we measured. Additionally, we consistently generated sigmoidal dose response curves with high $R^{2}$ and readily achieved $100 \%$ inhibition of development for our susceptible isolate. In contrast, data shown in Kitchen et al. [34] indicate that inhibition greater than $80 \%$ was not achieved and shapes of dose response curves were not sigmoidal. The cause of these differences is not readily apparent, but these are likely due to differences in the methods used in the two studies.

An additional interesting observation was that following treatment with fenbendazole, the egg counts in dogs infected with both the Tara and Worthy isolates initially decreased by greater than $99 \%$, but then steadily increased after treatment to rather high levels (Additional file 1: Table S1). Additionally, the mild clinical signs of enteritis that one of the dogs was displaying prior to treatment did not improve post-treatment. Given the EHA and $\beta$-tubulin SNP frequency data demonstrating extremely high levels of resistance in the surviving worms, the egg count and clinical response data suggest that the treatment was poorly effective in killing the worms, but induced a temporary inhibition of egg production. A similar temporary deleterious effect on worm fecundity has been reported previously for benzimidazoles in $H$. contortus in sheep [67], but is not recognized as an usual effect in nematodes of livestock following treatment with benzimidazoles. In contrast, this phenomenon has been reported on multiple occasions following treatment with ivermectin and moxidectin [68-70]. Regarding the reductions in FEC measured for pyrantel, for both isolates, it was clear that there was no effect of treatment (Figs. 3, 4).

Currently, the mechanisms of resistance to macrocyclic lactones and pyrantel in nematodes are unknown. Consequently, there are no molecular diagnostics available to detect resistance to these drug classes. However, the mechanism of resistance to benzimidazole drugs is well described. Benzimidazoles work by blocking the polymerization of parasite microtubules and they do this by binding to the nematode $\beta$-tubulin protein monomers $[71,72]$. SNPs in the isotype- $1 \beta$-tubulin gene located at codons 167 (TTC/Phe $\rightarrow$ TAC/Tyr), 198 (GAG/ $\mathrm{Glu} \rightarrow$ GCG/Ala $)$ and $200(\mathrm{TTC} / \mathrm{Phe} \rightarrow \mathrm{TAC} / \mathrm{Tyr})$ are associated with benzimidazole resistance in multiple species of strongylid nematode parasites such as Haemonchus contortus [72], Teladorsagia circumcincta [73] and cyathostomins [74]. Several PCR and pyrosequencing assays have been developed to detect and measure these mutations, [75-81] but these all have limitations that affect their usefulness.
However, a recently developed deep-amplicon sequencing assay for measuring benzimidazole-associated resistance mutations in nematode communities of cattle, sheep, bison and horses provides a powerful new tool that enables unparalleled sensitivity of detection and permits screening for the emergence of resistance mutations [48]. We modified and used this deep ampliconsequencing assay in $A$. caninum and here we report, to the best of our knowledge, the first use of this approach in a hookworm. Of the SNP associated with benzimidazole resistance in trichostrongylid nematodes, only F167Y (TTC > TAC) was detected. This same SNP has been commonly found in other strongylid nematode parasites such as equine cyathostomins [82], Haemonchus contortus [83], H. placei [84] and Teladorsagia circumcincta [85], and has only been rarely reported in Ascaris lumbricoides and Trichuris trichuira [40]. Recently, this same SNP was also reported in a resistant isolate of $A$. caninum that was originally isolated from a racing greyhound from Florida. Furthermore, using CRISPR/Cas 9, Kitchen et al. [34] were successful in replicating this SNP in the homologous ben-1 gene of C. elegans and saw a doubling of the resistance ratio in the EHA, which was similar to the resistance ratio measured in their A. caninum resistant isolate using the LDA [34].

Using deep amplicon sequencing, we found low allele frequencies for the benzimidazole resistance-associated SNPs in the susceptible isolates; in Barrow, the frequency was $1.2 \%$ and the two analyses for ETCR yielded highly variable results of 0 and $8.8 \%$. The reason for this discrepancy is not known and further analyses are in progress. In contrast, high SNP frequencies were recorded for all resistant isolates. The original isolate of Worthy had a SNP frequency of $92.2 \%$, which is consistent with the high selection pressure produced by the five rounds of intensive (10-day) fenbendazole treatment the dog received in the year prior to us collecting the sample. The lowest frequency measured in a resistant isolate was $12.7 \%$ in Tara, however, following a single treatment with fenbendazole, the SNP frequency increased to $50.9 \%$. It is unclear why Tara had a relatively low SNP frequency relative to the other resistant isolates, given that Tara had a history of multiple treatments with febantel prior to our receipt of the sample. Further analyses are in progress with all of our archived samples to address these issues. Interestingly, three single adult worms recovered from the feces of Lacy that we sequenced (out of many that were expelled alive after treatment with fenbendazole) had F167Y (TTC > TAC) SNP frequencies of approximately $50 \%$ indicating that these worms were heterozygous at codon 167. This was an interesting finding, as it suggests that heterozygous worms were able to survive the treatment, but could not maintain their position in 
the gastro-intestinal tract. In comparison, eggs recovered from the same feces demonstrated a SNP frequency of almost $100 \%$, suggesting that the worms that survived the treatment and maintained their position in the intestine were virtually all homozygous for resistance.

It is noteworthy that others have looked for benzimidazole resistance-associated SNP in A. caninum without success [86]. However, studies performed in Brazil did report finding a SNP at codon 198 in A. braziliense [87] and at codon 200 in A. caninum [88] at very low frequencies, 1.2 and $0.8 \%$, respectively, using PCR-RFLP. However, these findings were not confirmed by sequencing.

Here we report compelling evidence using in vitro, in vivo and genetic analyses that convincingly demonstrate that recent cases of hookworm in dogs that appear refractory to treatment, are due to A. caninum that are MDR. Although larval leak is likely involved in most of these cases, our data indicate strongly that MDR is the primary cause. This is an important and concerning development, as the emergence and spread of MDR $A$. caninum to all three major anthelmintic classes, would pose a serious threat to canine health, as there are no other effective drug classes currently approved for the treatment of hookworms in dogs in the USA. Although a recent study reported success in treating several cases of recurrent hookworm infections in greyhounds recently retired from racetracks using a combination therapy of moxidectin, pyrantel pamoate and febantel at monthly intervals [89], we have recently diagnosed multiple cases at a greyhound adoption kennel where this same regimen appears to be ineffective (data not shown). The disparity in these findings is consistent with the rapid evolution of moxidectin resistance when moxidectin is used against ivermectin resistant worms [61].

\section{Conclusions}

MDR in A. caninum is an emerging problem in dogs. Evidence suggests that the problem originated in the greyhound racing industry and has since begun to spread through the pet population. Nevertheless, we still lack definitive evidence to infer that these resistant hookworms are spreading into the pet dog population. Clearly, further epidemiological and molecular epidemiological investigations are needed in order to gain knowledge on the origin, prevalence and distribution of MDR A. caninum. Furthermore, new treatments approved for use in dogs are greatly needed. These results also provide proof of concept that anthelmintic resistance can arise in hookworm species. Ancylostoma caninum is extremely close phylogenetically to the hookworm species of humans, $A$. duodenale, A. ceylanicum and Necator americanus [90]. Consequently, these findings should provide some concern to the global health community, as the scale-up of mass drug administration for soil-transmitted helminths (STH) is now placing similar selection pressures for benzimidazole resistance in human hookworms and reduced efficacies are widely reported [91-96]. The deep amplicon sequencing assay used in this study, also can be used to perform global-level surveillance for the detection of benzimidazole resistance in human hookworms and with minor modifications, in roundworms (Ascaris lumbricoides) and whipworms (Trichuris trichiura).

\section{Supplementary information}

Supplementary information accompanies this paper at https://doi. org/10.1186/s13071-019-3828-6.

Additional file 1: Table S1. Fecal egg count reduction (FECR) data for fenbendazole, different post-treatment timepoints were tested. Fecal egg count reduction was calculated using the following formula: (Pre-treatment FEC - Post-treatment FEC) / (Pre-treatment FEC) × 100. Experimental infections in one dog each for the Tara and Worthy isolate.

\section{Abbreviations}

AR: antihelminthic resistance; EHA: egg hatch assays; LDA: larval developmental assays; FEC: fecal egg counts; FECR: fecal egg count reduction; ITS-2: internal transcribed spacer 2; MDR: multiple-drug resistant; SNP: single nucleotide polymorphisms.

\section{Acknowledgements}

We would like to thank Drs Linden Craig and Thomas W. Nauman, for providing samples, as well as Heidi Wyrosdick for sample processing, that helped make this work possible. We would also like to thank Drs. Kelsey Paras and Daniel Zuluaga and students Razan Sheikh and Dema Salih for their assistance in producing data for this manuscript. We are grateful to the Bill and Melinda Gates Foundation (Grant number ID OPP1172974) and NSERC-CREATE Host Pathogen Interactions Program at the University of Calgary for support (JSG and RWA).

\section{Authors' contributions}

RMK and JSG developed and directed the study. PDJC and SBH performed the in vitro studies and PDJC performed the in vivo studies and analysed the in vitro and in vivo data. RWA performed the molecular studies and analysed the molecular data. PDJC, RMK, RWA and JSG all contributed to the writing of the manuscript. JJS contacted RMK with the initial report of persistent hookworm infection, which led to the development of this project and provided the initial sample and case history. All authors read and approved the final manuscript.

\section{Funding}

There was no external funding for this study.

\section{Availability of data and materials}

The datasets supporting the conclusion of this article are included within the article and its additional file. The raw molecular data can be accessed via the following DOI link https://www.ncbi.nlm.nih.gov/sra/PRJNA556272.

Ethics approval and consent to participate

All in vivo experiments were carried out at the University of Georgia in accordance with the approved animal use protocol, AUP \# A2017 10-016-Y1-A0.

\section{Consent for publication}

Not applicable.

\section{Competing interests}

The authors declare that they have no competing interests. 


\begin{abstract}
Author details
1 Department of Infectious Diseases, College of Veterinary Medicine, University of Georgia, Athens, GA 30602, USA. ${ }^{2}$ Grupo de Parasitología Veterinaria, Universidad Nacional de Colombia, Bogotá, Colombia. ${ }^{3}$ School of Veterinary Medicine, Department of Biomedical and Diagnostic Sciences, University of Tennessee, Knoxville, USA. ${ }^{4}$ Department of Comparative Biology and Experimental Medicine, Faculty of Veterinary Medicine, University of Calgary, Calgary, Alberta, Canada.
\end{abstract}

Received: 23 August 2019 Accepted: 30 November 2019

Published online: 09 December 2019

\section{References}

1. Little SE, Johnson EM, Lewis D, Jaklitsch RP, Payton ME, Blagburn BL, et al. Prevalence of intestinal parasites in pet dogs in the United States. Vet Parasitol. 2009;166:144-52.

2. Drake J, Carey T. Seasonality and changing prevalence of common canine gastrointestinal nematodes in the USA. Parasites Vectors. 2019;12:430.

3. FDA. NADA 141-007 Drontal Plus. Silver Spring: Food and Drug Administration; 1994. https://animaldrugsatfda.fda.gov/adafda/views/\#/foiDr ugSummaries\#foiApplicationlnfo.

4. FDA. NADA 141-251 Advantage Multi. Silver Spring: Food and Drug Administration; 2006. https://animaldrugsatfda.fda.gov/adafda/views/\#/ foiDrugSummaries\#foiApplicationlnfo.

5. FDA. NADA 141-338 Interceptor Plus. Silver Spring: Food and Drug Administration; 2012. https://animaldrugsatfda.fda.gov/adafda/views/\#/ foiDrugSummaries\#foiApplicationlnfo.

6. FDA. NADA 121-473 Panacur. Silver Spring: Food and Drug Administration; 1983. https://animaldrugsatfda.fda.gov/adafda/views/\#/foiDrugSum maries\#foiApplicationlnfo.

7. FDA. NADA 141-008 Drontal. Silver Spring: Food and Drug Administration; 1993. https://animaldrugsatfda.fda.gov/adafda/views/\#/foiDrugSum maries\#foiApplicationlnfo.

8. Taylor M, Coop RL, Wall R. Vet Parasitol. Hoboken, NJ: Wiley Blackwell; 2016.

9. Epe C. Intestinal nematodes: biology and control. Vet Clin North Am Small Anim Pract. 2009;39:1091-107.

10. Kalkofen UP. Hookworms of dogs and cats. Vet Clin North Am Small Anim Pract. 1987;17:1341-54.

11. Stone WM, Girardeau M. Transmammary passage of Ancylostoma caninum larvae in dogs. J Parasitol. 1968;54:426-9.

12. Granzer M, Haas W. Host-finding and host recognition of infective Ancylostoma caninum larvae. Int J Parasitol. 1991;21:429-40.

13. Matsusaki G. Studies on the life history of the hookworm. Part VIl: on the development of Ancylostoma caninum in the abnormal host. Yokohama Med Bull. 1951;2:154-60.

14. Little MD. Observations on the possible role of insects as paratenic hosts for Ancylostoma caninum. J Parasitol. 1961;47:263-7.

15. Enigk K, Stoye M. Untersuchungen über den Infektionsweg von Ancylostoma caninum Ercolani 1859 (Ancylostomidae) beim Hund. Kongreßbericht über die III Tagung der Deutschen Tropenmedizinischen Gesellschaft, e V, Hamburg, vom. 1967;20:22.

16. Bowman DD. Georgis' parasitology for veterinarians. New York: Elsevier Health Sciences; 2014

17. Anderson RC. Nematode parasites of vertebrates. 2nd ed. Wallinford: CAB International; 2000

18. Schad GA. Ancylostoma duodenale: maintenance through six generations in helminth-native pups. Exp Parasitol. 1979;47:246-53.

19. Schad GA, Page MR. Ancylostoma caninum: adult worm removal, corticosteroid treatment, and resumed development of arrested larvae in dogs. Exp Parasitol. 1982;54:303-9.

20. Loukas A, Prociv P. Immune responses in hookworm infections. Clin Microbiol Rev. 2001;14:689-703.

21. Blouin MS, Yowell CA, Courtney CH, Dame JB. Host movement and the genetic structure of populations of parasitic nematodes. Genetics. 1995:141:1007-14.

22. Gilleard JS, Redman E. Genetic diversity and population structure of Haemonchus contortus. Adv Parasitol. 2016:93:31-68.
23. Prichard RK, Hall CA, Kelly JD, Martin IC, Donald AD. The problem of anthelmintic resistance in nematodes. Aust Vet J. 1980;56:239-51.

24. Wolstenholme AJ, Fairweather I, Prichard R, Samson-Himmelstjerna G, Sangster NC. Drug resistance in veterinary helminths. Trends Parasitol. 2004;20:469-76.

25. Ridley RK, Dryden MW, Gabbert NH, Schoning P. Epidemiology and control of helminth-parasites in greyhound breeding farms. Comp Cont Educ Pract. 1994;16:585-96.

26. Kaplan RM. Drug resistance in nematodes of veterinary importance: a status report. Trends Parasitol. 2004;20:477-81.

27. Jackson R, Lance D, Townsend K, Stewart K. Isolation of anthelmintic resistant Ancylostoma caninum. N Z Vet J. 1987;35:215-6.

28. Hopkins T, Gyr P, Hedemann P. Nematocidal and cesticidal efficacy of a tablet formulation containing febantel, pyranted embonate and praziquantel in dogs. Vet Med Rev. 1988;59:71-5.

29. Hopkins T, Gyr P. Synergism of a combination of febantel and pyrantel embonate against Ancylostoma caninum on dogs. Vet Med Rev. 1991;61:3-9.

30. Kopp SR, Kotze AC, McCarthy JS, Coleman GT. High-level pyrantel resistance in the hookworm Ancylostoma caninum. Vet Parasitol. 2007;143:299-304.

31. Kopp SR, Coleman GT, McCarthy JS, Kotze AC. Application of in vitro anthelmintic sensitivity assays to canine parasitology: detecting resistance to pyrantel in Ancylostoma caninum. Vet Parasitol. 2008;152:284-93.

32. Kopp SR, Coleman GT, McCarthy JS, Kotze AC. Phenotypic characterization of two Ancylostoma caninum isolates with different susceptibilities to the anthelmintic pyrantel. Antimicrob Agents Chemother. 2008;52:3980-6.

33. Thompson RCA. The future impact of societal and cultural factors on parasitic disease_-some emerging issues. Int J Parasitol. 2001;31:949-59.

34. Kitchen S, Ratnappan R, Han S, Leasure C, Grill E, Iqbal Z, et al. Isolation and characterization of a naturally occurring multidrug-resistant strain of the canine hookworm, Ancylostoma caninum. Int J Parasitol. 2019;49:397-406.

35. Leeming JA. Cutaneous larva migrans. S Afr Med J. 1966:40:403-5.

36. Prociv $\mathrm{P}$, Croese J. Human enteric infection with Ancylostoma caninum: hookworms reappraised in the light of a "new" zoonosis. Acta Trop. 1996;62:23-44.

37. Ngcamphalala PI, Lamb J, Mukaratirwa S. Molecular identification of hookworm isolates from stray dogs, humans and selected wildlife from South Africa. J Helminthol. 2019;94:e39.

38. Sulston J, Hodgkin J. In: Wood WB, editor. The nematode Caenorhabditis elegans. Cold Spring Harbor: Cold Spring Harbor Laboratory Press; 1988. p. 587-606.

39. Coles GC, Simpkin KG. Resistance of nematode eggs to the ovicidal activity of benzimidazoles. Res Vet Sci. 1977;22:386-7.

40. Diawara A, Schwenkenbecher JM, Kaplan RM, Prichard RK. Molecular and biological diagnostic tests for monitoring benzimidazole resistance in human soil-transmitted helminths. Am J Trop Med Hyg. 2013;88:1052-61.

41. Kotze AC, Lowe A, O'Grady J, Kopp SR, Behnke JM. Dose-response assay templates for in vitro assessment of resistance to benzimidazole and nicotinic acetylcholine receptor agonist drugs in human hookworms. Am J Trop Med Hyg. 2009:81:163-70.

42. Howell SB, Burke JM, Miller JE, Terrill TH, Valencia E, Williams MJ, et al. Prevalence of anthelmintic resistance on sheep and goat farms in the southeastern United States. J Am Vet Med Assoc. 2008;233:1913-9.

43. Tandon R, Kaplan RM. Evaluation of a larval development assay (DrenchRite) for the detection of anthelmintic resistance in cyathostomin nematodes of horses. Vet Parasitol. 2004;121:125-42.

44. Martin RJ. Modes of action of anthelmintic drugs. Vet J. 1997:154:11-34.

45. Maurelli MP, Rinaldi L, Alfano S, Pepe P, Coles GC, Cringoli GJP, et al. MiniFLOTAC, a new tool for copromicroscopic diagnosis of common intestinal nematodes in dogs. Parasit Vectors. 2014;7:356

46. Lima VF, Cringoli G, Rinaldi L, Monteiro MF, Calado AM, Ramos RA, et al. A comparison of mini-FLOTAC and FLOTAC with classic methods to diagnosing intestinal parasites of dogs from Brazil. Parasitol Res. 2015;114:3529-33.

47. Avramenko RW, Redman EM, Lewis R, Yazwinski TA, Wasmuth JD, Gilleard JS. Exploring the gastrointestinal "Nemabiome": deep amplicon sequencing to quantify the species composition of parasitic nematode communities. PLoS One. 2015;10:e0143559. 
48. Avramenko RW, Redman EM, Melville L, Bartley Y, Wit J, Queiroz C, et al. Deep amplicon sequencing as a powerful new tool to screen for sequence polymorphisms associated with anthelmintic resistance in parasitic nematode populations. Int J Parasitol. 2019;49:13-26.

49. Avramenko RW, Redman EM, Lewis R, Bichuette MA, Palmeira BM, Yazwinski TA, et al. The use of nemabiome metabarcoding to explore gastro-intestinal nematode species diversity and anthelmintic treatment effectiveness in beef calves. Int J Parasitol. 2017;47:893-902.

50. Jacobs DE, Prole JHB. Helminth infections of British dogs: prevalence in racing greyhounds. Vet Parasitol. 1976;1:377-87.

51. Ash A, Lymbery A, Godfrey S, Shiel R, Paul A. Substrate type and age are risk factors for gastrointestinal parasitism in greyhound kennels. Vet Parasitol. 2019;265:7-14.

52. Martin PJ, Le Jambre LF, Claxton JH. The impact of refugia on the development of thiabendazole resistance in Haemonchus contortus. Int J Parasitol. 1981;11:35-41.

53. Le Jambre LF. Egg hatch as an in vitro assay of thiabendazole resistance in nematodes. Vet Parasitol. 1976;2:385-91.

54. Hunt KR, Taylor MA. Use of the egg hatch assay on sheep faecal samples for the detection of benzimidazole resistant nematodes. Vet Rec. 1989;125:153-4.

55. von Samson-Himmelstierna G, Coles GC, Jackson F, Bauer C, Borgsteede F, Cirak VY, et al. Standardization of the egg hatch test for the detection of benzimidazole resistance in parasitic nematodes. Parasitol Res. 2009;105:825-34.

56. Rialch A, Vatsya S, Kumar RR. Detection of benzimidazole resistance in gastrointestinal nematodes of sheep and goats of sub-Himalyan region of northern India using different tests. Vet Parasitol. 2013;198:312-8.

57. Varady M, Biorn H, Nansen P. In vitro characterization of anthelmintic susceptibility of field isolates of the pig nodular worm Oesophagostomum spp. susceptible or resistant to various anthelmintics. Int J Parasitol. 1996;26:733-40.

58. Kotze AC, Coleman GT, Mai A, McCarthy JS. Field evaluation of anthelmintic drug sensitivity using in vitro egg hatch and larval motility assays with Necator americanus recovered from human clinical isolates. Int J Parasitol. 2005;35:445-53.

59. Albonico M, Wright V, Ramsan M, Haji HJ, Taylor M, Savioli L, et al. Development of the egg hatch assay for detection of anthelminthic resistance in human hookworms. Int J Parasitol. 2005;35:803-11.

60. Raza A, Lamb J, Chambers M, Hunt PW, Kotze AC. Larval development assays reveal the presence of sub-populations showing high- and lowlevel resistance in a monepantel (Zolvix ${ }^{\circledR}$ )-resistant isolate of Haemonchus contortus. Vet Parasitol. 2016;220:77-82.

61. Kaplan RM, Vidyashankar AN, Howell SB, Neiss JM, Williamson LH, Terrill $\mathrm{TH}$. A novel approach for combining the use of in vitro and in vivo data to measure and detect emerging moxidectin resistance in gastrointestinal nematodes of goats. Int J Parasitol. 2007;37:795-804.

62. Gill JH, Redwin JM, van Wyk JA, Lacey E. Avermectin inhibition of larval development in Haemonchus contortus - effects of ivermectin resistance. Int J Parasitol. 1995;25:463-70.

63. Craven J, Bjorn H, Barnes EH, Henriksen SA, Nansen P. A comparison of in vitro tests and a faecal egg count reduction test in detecting anthelmintic resistance in horse strongyles. Vet Parasitol. 1999:85:49-59.

64. Prichard R, Ménez C, Lespine A. Moxidectin and the avermectins: consanguinity but not identity. Int J Parasitol Drugs Drug Resist. 2012;2:134-53.

65. Craig TM, Hatfield TA, Pankavich JA, Wang GT. Efficacy of moxidectin against an ivermectin-resistant strain of Haemonchus contortus in sheep. Vet Parasitol. 1992;41:329-33.

66. Oosthuizen WT, Erasmus JB. Efficacy of moxidectin against a strain of Haemonchus contortus resistant to ivermectin, a benzimidazole and a salicylanilide. J S Afr Vet Assoc. 1993;64:9-12.

67. Scott EW, Baxter P, Armour J. Fecundity of anthelmintic resistant adult Haemonchus contortus after exposure to ivermectin or benzimidazoles in vivo. Res Vet Sci. 1991;50:247-9.

68. McKellar QA, Bogan JA, Horspool L, Reid K. Effect of ivermectin on the reproductive potential of Cooperia curticei. Vet Rec. 1988;122:444.

69. Sutherland IA, Leathwick DM, Brown AE. Moxidectin: persistence and efficacy against drug-resistant Ostertagia circumcincta. J Vet Pharmacol Ther. 1999;22:2-5.

70. Condi GK, Soutello RG, Amarante AF. Moxidectin-resistant nematodes in cattle in Brazil. Vet Parasitol. 2009;161:213-7.
71. Lacey E. The role of the cytoskeletal protein, tubulin, in the mode of action and mechanism of drug resistance to benzimidazoles. Int J Parasitol. 1988;18:885-936.

72. Kwa MS, Veenstra JG, Roos MH. Benzimidazole resistance in Haemonchus contortus is correlated with a conserved mutation at amino acid 200 in beta-tubulin isotype 1. Mol Biochem Parasitol. 1994;63:299-303.

73. Elard $L$, Comes AM, Humbert JF. Sequences of beta-tubulin CDNA from benzimidazole-susceptible and -resistant strains of Teladorsagia circumcincta, a nematode parasite of small ruminants. Mol Biochem Parasitol. 1996;79:249-53.

74. von Samson-Himmelstjerna G, Harder A, Pape M, Schnieder T. Novel small strongyle (Cyathostominae) beta-tubulin sequences. Parasitol Res. 2001:87:122-5.

75. von Samson-Himmelstjerna G, Walsh TK, Donnan AA, Carriere S, Jackson F, Skuce PJ, et al. Molecular detection of benzimidazole resistance in Haemonchus contortus using real-time PCR and pyrosequencing. Parasitology. 2009;136:349-58.

76. Chaudhry U, Miller M, Yazwinski T, Kaplan R, Gilleard J. The presence of benzimidazole resistance mutations in Haemonchus placei from US cattle. Vet Parasitol. 2014;204:411-5.

77. Knapp-Lawitzke F, Krücken J, Ramünke S, von Samson-Himmelstjerna G, Demeler J. Rapid selection for $\beta$-tubulin alleles in codon 200 conferring benzimidazole resistance in an Ostertagia ostertagi isolate on pasture. Vet Parasitol. 2015;209:84-92.

78. Álvarez-Sánchez MA, Pérez-García J, Cruz-Rojo MA, Rojo-Vázquez FA. Real time PCR for the diagnosis of benzimidazole resistance in trichostrongylids of sheep. Vet Parasitol. 2005;129:291-8.

79. Demeler J, Krüger N, Krücken J, von der Heyden VC, Ramünke S, Küttler $U$, et al. Phylogenetic characterization of $\beta$-Tubulins and development of pyrosequencing assays for benzimidazole resistance in cattle nematodes. PLoS One. 2013;8:e70212.

80. Redman E, Whitelaw F, Tait A, Burgess C, Bartley Y, Skuce PJ, et al. The emergence of resistance to the benzimidazole anthlemintics in parasitic nematodes of livestock is characterised by multiple independent hard and soft selective sweeps. PLoS Negl Trop Dis. 2015;9:e0003494.

81. Ramünke S, Melville L, Rinaldi L, Hertzberg H, de Waal T, von SamsonHimmelstjerna G, et al. Benzimidazole resistance survey for Haemonchus, Teladorsagia and Trichostrongylus in three European countries using pyrosequencing including the development of new assays for Trichostrongylus. Int J Parasitol Drugs Drug Resist. 2016;6:230-40.

82. Hodgkinson JE, Clark HJ, Kaplan RM, Lake SL, Matthews JB. The role of polymorphisms at beta tubulin isotype 1 codons 167 and 200 in benzimidazole resistance in cyathostomins. Int J Parasitol. 2008;38:1149-60.

83. Prichard R. Genetic variability following selection of Haemonchus contortus with anthelmintics. Trends Parasitol. 2001;17:445-53.

84. Brasil BS, Nunes RL, Bastianetto E, Drummond MG, Carvalho DC, Leite RC, et al. Genetic diversity patterns of Haemonchus placei and Haemonchus contortus populations isolated from domestic ruminants in Brazil. Int J Parasitol. 2012;42:469-79.

85. Silvestre A, Cabaret J. Mutation in position 167 of isotype 1 beta-tubulin gene of trichostrongylid nematodes: role in benzimidazole resistance? Mol Biochem Parasitol. 2002;120:297-300.

86. Furtado LF, Rabelo ÉM. Molecular analysis of the F167Y SNP in the beta-tubulin gene by screening genotypes of two Ancylostoma caninum populations. Vet Parasitol. 2015;210:114-7.

87. Furtado LFV, Magalhães JGS, Rabelo ÉML. Standardization and application of a modified RFLP-PCR methodology for analysis of polymorphisms linked to treatment resistance in Ancylostoma braziliense. Parasit Vectors. 2018;11:540.

88. Furtado LF, Bello AC, dos Santos HA, Carvalho MR, Rabelo ÉM. First identification of the F200Y SNP in the $\beta$-tubulin gene linked to benzimidazole resistance in Ancylostoma caninum. Vet Parasitol. 2014;206:313-6.

89. Hess LB, Millward LM, Rudinsky A, Vincent E, Marsh A. Combination anthelmintic treatment for persistent Ancylostoma caninum ova shedding in greyhounds. J Am Anim Hosp Assoc. 2019;55:160-6.

90. Blaxter M. Genes and genomes of Necator americanus and related hookworms. Int J Parasitol. 2000;30:347-55.

91. Speich B, Moser W, Ali SM, Ame SM, Albonico M, Hattendorf J, et al. Efficacy and reinfection with soil-transmitted helminths 18-weeks posttreatment with albendazole-ivermectin, albendazole-mebendazole, 
albendazole-oxantel pamoate and mebendazole. Parasit Vectors. 2016;9:123.

92. Flohr C, Tuyen LN, Lewis S, Minh TT, Campbell J, Britton J, et al. Low efficacy of mebendazole against hookworm in Vietnam: two randomized controlled trials. Am J Trop Med Hyg. 2007;76:732-6.

93. Albonico M, Bickle Q, Ramsan M, Montresor A, Savioli L, Taylor M. Efficacy of mebendazole and levamisole alone or in combination against intestinal nematode infections after repeated targeted mebendazole treatment in Zanzibar. Bull World Health Organ. 2003:81:343-52.

94. De Clercq D, Sacko M, Behnke J, Gilbert F, Dorny P, Vercruysse J. Failure of mebendazole in treatment of human hookworm infections in the southern region of Mali. Am J Trop Med Hyg. 1997;57:25-30.
95. Albonico M, Wright V, Bickle Q. Molecular analysis of the beta-tubulin gene of human hookworms as a basis for possible benzimidazole resistance on Pemba Island. Mol Biochem Parasitol. 2004;134:281-4.

96. Albonico M, Smith PG, Hall A, Chwaya HM, Alawi KS, Savioli L. A randomized controlled trial comparing mebendazole and albendazole against Ascaris, Trichuris and hookworm infections. Trans R Soc Trop Med Hyg. 1994;88:585-9.

\section{Publisher's Note}

Springer Nature remains neutral with regard to jurisdictional claims in published maps and institutional affiliations.
Ready to submit your research? Choose BMC and benefit from:

- fast, convenient online submission

- thorough peer review by experienced researchers in your field

- rapid publication on acceptance

- support for research data, including large and complex data types

- gold Open Access which fosters wider collaboration and increased citations

- maximum visibility for your research: over $100 \mathrm{M}$ website views per year

At BMC, research is always in progress.

Learn more biomedcentral.com/submissions 